\section{P88 RELATIONSHIP BETWEEN EXHALED NITRIC OXIDE AND LUNG CLEARANCE INDEX IN PRE-SCHOOL CHILDREN WITH A RANGE OF RESPIRATORY SYMPTOMS}

${ }^{1} Y$ Bingham, ${ }^{2} \mathrm{~N}$ Sanghani, ${ }^{2} \mathrm{~S}$ Irving, ${ }^{1} \mathrm{~A}$ Bush, ${ }^{1} \mathrm{~L}$ Fleming, 'S Saglani. ${ }^{1}$ Imperial College London, London, UK; ${ }^{2}$ Royal Brompton and Harefield NHS Foundation Trust, London, UK

\subsection{6/thoraxjnl-2017-210983.230}

Introduction Both exhaled nitric oxide (FeNO), a non-invasive marker of eosinophilic airway inflammation, and lung clearance index (LCI), an effort independent assessment of distal airway function, are increased in pre-school children with multiple trigger wheezing (Sonnappa JACI 2010;126:519-26). However, whether there is any relationship between the two measures is unknown. We hypothesised that FeNO and LCI are positively related in pre-school children with a range of respiratory symptoms and this relationship would be strongest in pre-school wheeze.

Methods Patients aged between 2 and 6 years were recruited from the paediatric respiratory department at our tertiary centre. FeNO was measured using the offline technique (Niox Mino, Aerocrine AB, Sweden) and LCI was measured using the multiple breath washout technique (Sulphur hexafluoride tracer gas, photoacoustic gas analyser (Innocor, Innovision, Denmark)).

Results 19 children (median age 4.2, range 2.7-5.8 years) had assessments of both FeNO and LCI on the same day. Respiratory diagnoses were: multiple trigger wheeze (MTW) $n=10$, episodic viral wheeze (EVW) $n=5$, cough $n=1$, recurrent infections $n=1$, obliterative bronchiolitis $(O B) n=1$, sleep disordered breathing $n=1$. A significant correlation was found between FeNO and LCI, in pre-school children with respiratory symptoms (Spearman correlation coefficient $\mathrm{r}=0.5$, $\mathrm{p}=0.02$ ) (figure 1). When the MTW and EVW groups were compared, there was no correlation between FeNO and LCI in EVW, but there was a significant relationship in MTW $(\mathrm{r}=0.6, \mathrm{p}=0.05)$.

Conclusions There was a positive relationship between FeNO and LCI in pre-school children with a range of respiratory symptoms. The relationship was strongest in those with recurrent multiple trigger wheeze. These data provide further evidence for different pathophysiologies in MTW and EVW, implying the need for different treatment approaches.

\section{FeNO and $\mathrm{LCl}$}

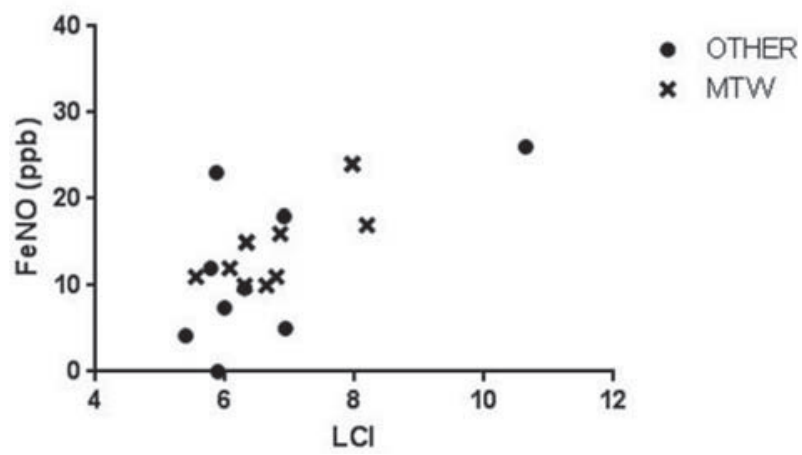

Abstract P88 Figure 1 Relationship between offline exhaled nitric oxide (FeNO) and lung clearance index (LCl). MTW: multiple trigger wheeze.

\section{P89 \\ VENTILATION HETEROGENEITY IS A FEATURE OF CHILDREN WITH SEVERE ASTHMA AND NORMAL SPIROMETRY}

${ }^{1} \mathrm{~A}$ Nuttall, ${ }^{2} \mathrm{C}$ Beardsmore, ${ }^{3} \mathrm{E}$ Gaillard. ${ }^{1}$ Department of Infection, Immunity and Inflammation, College of Medicine, Biological Sciences and Psychology, University of Leicester, Leicester, UK; ${ }^{2}$ Department of Infection, Immunity and Inflammation, College of Medicine, Biological Sciences and Psychology, Leicester Institute for Lung Health, NIHR Leicester Respiratory Biomedical Research Unit, University of Leicester, Leicester, UK; ${ }^{3}$ Department of Infection, Immunity and Inflammation, College of Medicine, Biological Sciences and Psychology, Leicester Institute for Lung Health, NIHR Leicester Respiratory Biomedical Research Unit, University of Leicester and University Hospitals of Leicester NHS Trust, Leicester, UK

\subsection{6/thoraxjnl-2017-210983.231}

Introduction Ventilation heterogeneity $(\mathrm{VH})$ is a feature of a subgroup of adults with asthma (Verbanck et al. AJRCCM 1999; 159.5:1545-1550), however less is known regarding $\mathrm{VH}$ in childhood asthma. Previous data indicates $\mathrm{VH}$ is raised in asthmatic children compared with controls, and may be particularly high in those with severe or poorly controlled asthma. This may be important as many children report poor symptom control, despite normal spirometry.

Objectives We aimed to study the relationship between ventilation heterogeneity, disease severity, and symptom control in children with asthma.

Methods Stable asthmatic children were recruited from the Difficult Asthma Clinic, with controls recruited from diabetes clinic patients and their siblings. Asthma severity was classified in accordance with GINA guidelines (Step 1-3=Mild Moderate, Step $4-5=$ Severe). Asthmatics completed C-ACT/ACT to assess symptom control (score $\leq 19=$ uncontrolled). All children performed Spirometry. Ventilation heterogeneity was assessed using Multiple-Breath Nitrogen Washout (MBNW) (Exhalyzer-D, Ecomedics). MBNW was performed in triplicate, with Lung Clearance Index (LCI) and indices of ventilatory heterogeneity in conductive and acinar airways ( $S_{\text {cond }}$ and $\mathrm{S}_{\mathrm{acin}}$, respectively) calculated.

Abstract P89 Table 1 MBNW results, displayed as median (range). Comparisons made using mann-whitney test, ${ }^{*} p<0.05=$ significant

\begin{tabular}{lllll}
\hline Controls $\mathrm{n}=7$ & $\begin{array}{l}\text { Mild-Moderate } \\
\text { Asthma } \mathrm{n}=7\end{array}$ & $\begin{array}{l}\text { Severe } \\
\text { Asthma } \mathrm{n}=\mathbf{2 1}\end{array}$ & $\begin{array}{l}\text { Mild-Moderate vs } \\
\text { Severe Asthma }\end{array}$ \\
\hline $\mathrm{LCl}$ & 6.48 & 6.69 & 7.50 & $\mathrm{p}=0.023^{*}$ \\
& $(5.78-7.03)$ & $(5.63-7.40)$ & $(5.79-9.79)$ & \\
$\mathrm{S}_{\text {cond }}$ & 0.014 & 0.016 & 0.026 & $\mathrm{p}=0.186$ \\
& $(0.008-0.022)$ & $(0.007-0.051)$ & $(0.009-0.079)$ & \\
$\mathrm{S}_{\text {acin }}$ & 0.055 & 0.054 & 0.082 & $\mathrm{p}=0.291$ \\
& $(0.035-0.077)$ & $(0.043-0.158)$ & $(0.044-0.151)$ & \\
\hline
\end{tabular}

Results 35 participants aged 7-16 completed testing (7 controls, 7 mild-moderate asthma, 21 severe asthma). Results for MBNW displayed in Table 1. All MBNW parameters were normal in control subjects. Only the severe asthmatics had MBNW Results significantly higher than controls (LCI $\left.\mathrm{p}=0.006, \mathrm{~S}_{\text {cond }} \mathrm{p}=0.021, \mathrm{~S}_{\text {acin }} \mathrm{p}=0.040\right)$. LCI was raised in $1 /$ 7 mild-moderate and $13 / 21$ severe asthmatics. $S_{\text {cond }}$ was raised in 2/7 mild-moderate and 11/21 severe asthmatics. $S_{\text {acin }}$ was raised in 1/7 mild-moderate and 4/21 severe asthmatics. 18/28 asthmatics had uncontrolled symptoms as assessed by the C- 
ACT/ACT. Of these, 14 had abnormal LCI but only 4 had abnormal $\mathrm{FEV}_{1}$. 8/28 asthmatics had raised LCI despite normal $\mathrm{FEV}_{1}$.

Conclusions LCI, a measure of ventilation heterogeneity, is raised in a high proportion of children with severe asthma. Most children with raised LCI had normal spirometry. This suggests that LCI is more sensitive to detect lung function deficits in asthma compared to spirometry. LCI also correlates well with symptom control. MBNW and LCI may be useful in the monitoring of children with severe asthma.

\section{P90 HOW DOES BMI STATUS INFLUENCE SPIROMETRY AND RESPIRATORY MUSCLE STRENGTH IN CHILDREN?}

${ }^{1} \mathrm{GSJ}$ Duncan, ${ }^{1} \mathrm{NT}$ Gharbawi, ${ }^{2} \mathrm{M}$ Viskaduraki, ${ }^{1} \mathrm{EA}$ Gaillard, ${ }^{1} \mathrm{CS}$ Beardsmore. ${ }^{1}$ Department of Infection, Immunity and Inflammation (Child Health), University of Leicester, Leicester, UK; ${ }^{2}$ Bioinformatics and Biostatistics Hub, College of Medicine, Biology and Psychology, University of Leicester, Leicester, UK

\subsection{6/thoraxjnl-2017-210983.232}

Introduction While BMI correlates positively with spirometry during childhood, young children who are overweight or obese have been shown to have a reduced $\mathrm{FEV}_{1} / \mathrm{FVC}$ compared to their peers. ${ }^{1}$ In childhood, obesity has been shown to have a negative effect upon inspiratory muscle strength. ${ }^{2}$

Aims To assess whether there are differences in spirometry of children of varying BMI status and whether this relates to respiratory muscle strength.

Methods Within schools, we measured each child's height, weight, and spirometry. Respiratory muscle strength was assessed via maximal inspiratory and expiratory pressures (MIP/MEP). The child breathed through a pneumotachograph attached to a shutter. To measure MIP, the child exhaled maximally and the shutter was activated. The child made an inspiratory effort against the shutter and peak pressure was recorded. The test was repeated several times. Measurements of MEP were similar, except that the child inhaled maximally and then made a forceful expiratory effort. We calculated BMI and grouped children by centile score into underweight, healthy, overweight or obese, using epidemiological cut-offs. Results were adjusted for age and height via an ANCOVA.

Results We studied 297 children (5-11 year). We obtained data for spirometry in 258, MIP in 231 and MEP in 262. Mean adjusted values are shown (Table). All individual parameters showed significant positive correlation with BMI, while $\mathrm{FEV}_{1} / \mathrm{FVC}$ was significantly negatively correlated with BMI. The obese group had a significantly greater adjusted mean value for MEP than the healthy group and a significantly greater mean adjusted value for FVC than the underweight group, while having a significantly lower mean adjusted $\mathrm{FEV}_{1} /$ FVC than both healthy and underweight groups.

Conclusion Despite having the greatest adjusted mean value for expiratory muscle strength and vital capacity, the obese group demonstrated the lowest adjusted mean $\mathrm{FEV}_{1} / \mathrm{FVC}$, indicating a potential alteration in respiratory flow dynamics for children of greater BMI.

\section{REFERENCES}

1. Tantisira, et al. Thorax 2003, Dec;58(12):1036-41.

2. da Rosa, et al. Rev Paul Pediatr 2014, Jun;32(2):250-5.
Abstract P90 Table 1

\begin{tabular}{lllll}
\hline & Underweight & Healthy & Overweight & Obese \\
\hline FEV $_{1}(\mathrm{~L})$ & 1.55 & 1.69 & 1.69 & 1.67 \\
FVC (L) & 1.70 & 1.90 & 1.94 & 1.97 \\
FEV $_{1} / \mathrm{FVC}$ & 91.2 & 89.1 & 87.7 & 85.7 \\
$(\%)$ & & & \\
MIP (kPa) & 6.89 & 7.07 & 7.68 & 7.57 \\
MEP (kPa) & 6.01 & 6.29 & 6.54 & 7.12 \\
\hline
\end{tabular}

\section{Multi-morbidity in COPD}

\section{P91 HIGH PREVALENCE OF VITAMIN D DEFICIENCY AMONGST PATIENTS WITH COPD IN THE NORTH EAST. HIGHLIGHTING A DEFICIENCY AND NEED FOR IMPROVED ASSESSMENT}

H Tedd, K Conroy, A Mitchell, Y Shanshal, H Curtis. Queen Elizabeth Hospital, Gateshead, UK

\subsection{6/thoraxjnl-2017-210983.233}

Background Vitamin D plays a key role in osteoporosis and also contributes to sarcopenia, muscle weakness, fatigue and depression. Patients with COPD are likely to be at higher risk of Vitamin D deficiency due to reduced mobility especially outdoors, with previous studies in the London area demonstrating prevalence rates around $60 \% .{ }^{1}$ However, within our population group in the North East of England, little is known about the prevalence of Vitamin D deficiency.

Aims To identify the prevalence of serum 25-hydroxyvitamin D (25(OH)-D) deficiency in patients admitted with an acute exacerbation of COPD.

Method We identified 50 patients admitted with an exacerbation of COPD. Data on demographics and prescription of vitamin D supplementation was recorded. 25(OH)-D titres were measured.

Results 50 patients included, mean age 73.6 years (age range 45-95 years). $44 \%$ of patients were prescribed vitamin D supplementation (95\% of supplementation was in the form of combined calcium and vitamin D). Overall $62 \%$ of patients were found to have low 25(OH)-D titres. Of those not taking vitamin D supplementation, only $14 \%$ of patient had sufficient $25(\mathrm{OH})$-D titres $(\geq 50 \mathrm{nmol} / \mathrm{L}) .11 \%$ were $25(\mathrm{OH})$-D insufficient $(30-50 \mathrm{nmol} / \mathrm{L}), \quad 57 \%$ were $25(\mathrm{OH})-\mathrm{D}$ deficient $(8-$ $30 \mathrm{nmol} / \mathrm{L})$ and $18 \%$ were profoundly deficient $(<8 \mathrm{nmol} / \mathrm{L})$. Of those patients taking vitamin D supplementation, $68 \%$ were found to have sufficient $25(\mathrm{OH})$-D titres, whilst $32 \%$ still had inadequate $25(\mathrm{OH})$-D highlighting potential issues with compliance or insufficient replacement.

Conclusions We have demonstrated a very high prevalence of vitamin D deficiency amongst our patients with COPD, with $86 \%$ of our patients having inadequate vitamin $\mathrm{D}$ titres who were not on vitamin D supplementation. This is leading them to increased exposure to the risks of vitamin D deficiency, including the impact on bone health in at already 'at-risk' population. In response to this, locally we are now measuring 25(OH)-D titres routinely on patients with COPD and prescribing vitamin D supplementation when indicated, forming 